\title{
A Rare Case of Fibrolamellar Hepatocellular Carcinoma with Unusual Presentation in a Young Indian Female- a case report
}

\author{
Nayak R ${ }^{1}$, Jain $\mathbf{S}^{2}$ \\ ${ }^{1}$ Dr. Rashmi Nayak, Assistant professor, Department of Pathology, NSCB Medical College Jabalpur (MP) India, ${ }^{2}$ Dr. Sharad \\ Jain, Associate professor, Department of Pathology, NSCB Medical College Jabalpur (M.P.) India.
}

Address of corresponding author: Dr Rashmi Nayak, E mail: vijaynayak123@gmail.com

\begin{abstract}
Fibrolamellar carcinoma (FLC) is a rare subtype of Hepatocellular carcinoma (HCC) comprising Approx 1\% of HCC. This variant of HCC commonly metastasizes to regional lymph nodes (celiac, gastric, para aortic). But metastasis to cervical lymph nodes is very rare. It is also very rare in Asian population. We are reporting a case of a rare cervical lymph node metastasis from FLC in an Indian female. Patient was a 20 yrs female presented with a cervical lymph node enlargement. USG and CT revealed lesion in liver and massive lymphadenopathy involving regional and para aortic group of lymph nodes. Diagnosis was made on histopathological examination of cervical lymph node biopsy.
\end{abstract}

Key words: Fibrolamellar carcinoma, hepatocellular carcinoma, Hepatic carcinoma

\section{Introduction}

Fibrolamellar carcinoma (FLC) is a rare variant of HCC comprising Approx 1\% of HCC [1]. It is common in US and Europe [1]. In Asia it is very rare. It was initially described by Edmondson in 1956 [2]. Clinically FLC usually present with abdominal pain and metastasize to regional lymph nodes (Cealic, gastric, paraaortic).

Metastasis to cervical lymph node is rarely observed in FLC. The most characteristic Histologic feature of FLC is fibrosis arranged in a lamellar fashion around the neoplastic hepatocytes.

The tumor cells are large polygonal with abundant eosinophilic cytoplasm, vesicular nuclei and prominent nucleoli [3]. We have reported a rare variant of HCC (i.e. FLC) in an Indian female presented with cervical lymph node metastasis which is an unusual presentation.

\section{Case report}

We are reporting a case of $20 \mathrm{yrs}$ Indian female presented with a lump in the upper cervical region. There were no other complaints except for mild abdominal discomfort. Systemic evaluation revealed hepatomegaly. Her laboratory test showed CBC and ESR within normal limits. Liver profile and kidney profile were also normal.

\footnotetext{
Manuscript received: $29^{\text {th }}$ May 2014

Reviewed: $15^{\text {th }}$ June 2014

Author Corrected: $20^{\text {th }}$ June 2014

Accepted for Publication: $6^{\text {th }}$ July 2014
}

USG report showed pre and para-aortic

lymphadenopathy with borderline hepatomegaly and septate gallbladder filled with sludge. USG guided FNAC was done which showed plenty of normal hepatocytes along with acute and chronic inflammatory cells in a necrotic background. Smear was Negative for malignancy.

CT report showed multiple nodules in the liver. There were significant lymph nodes along the portal vein that were seen to compress the common bile duct with mild dilatation of intrahepatic bile ducts. Gallbladder was dilated and its fundus showed significantly thicken wall.

Massive lymhadenopathies was seen within retroperitoneum from renal vein level to the level of aortic bifurcation. Lymphnodes were also seen along IVC and coelic plane \& peripancreatic area.

There was ascites and bilateral pleural effusion. CT guided FNAC from left paraaortic nodes was done but it was not informative as it showed only haemorrhagic aspirate. After seeing the reports clinicians were suspecting it to be a case of Hodgkins lymphoma and excision biopsy from enlarged cervical lymph node was send to our department for histopathological examination which revealed metastatic deposits from Fibrolamellar variant of hepatocellular carcinoma.

Available online at: www.ijmrr.in 385 | P a g e 


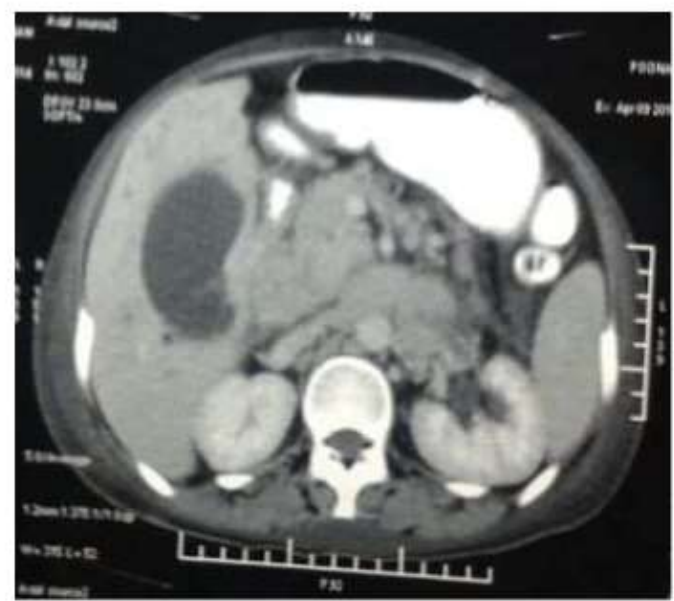

Figure 1: CT showing a large nodule in left lobe of liver the large nodule in left lobe of liver
Case Report

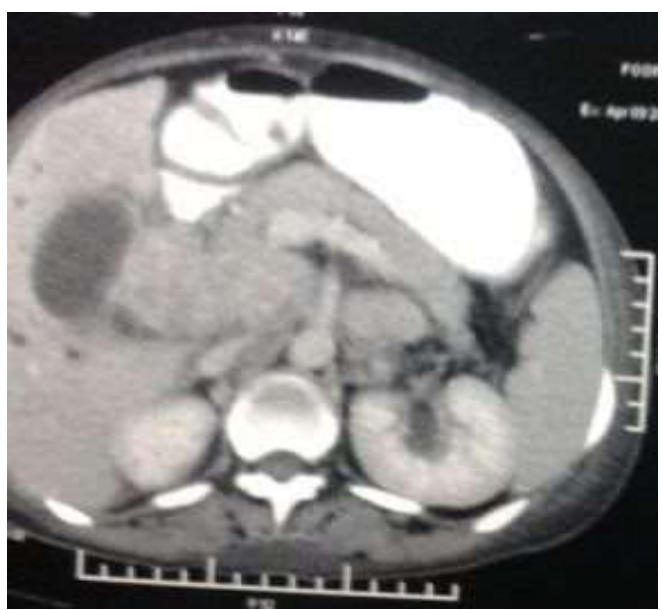

Figure 1: CT showing multiple small nodules around

\section{Histopathology Report}

$\mathrm{H} / \mathrm{E}$ stained sections from cervical lymph node biopsy show malignant epithelial cell effacing the normal lymph node architecture. Cells are large polygonal having large vesicular nuclei with prominent nucleoli and abundant eosinophilic cytoplasm. The cells are arranged in trabecular and acinar pattern, and are separated by fibroconnective tissue. Features are suggestive of metastatic deposits from Fibrolamellar variant of Hepatocellular carcinoma.

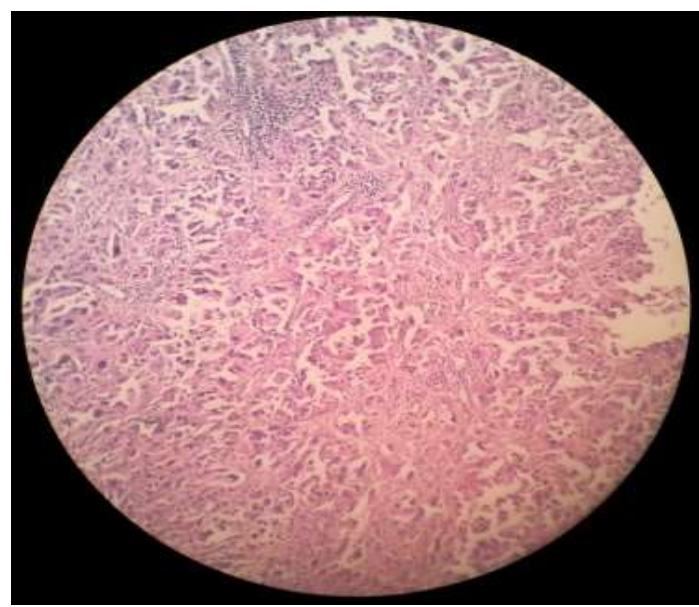

Fig 3: Complete effacement of lymph node architecture by neoplastic cells

\section{Discussion}

FLC is a rare morphologic variant of HCC which is not associated with cirrhosis or other chronic liver disease and having a generally favorable prognosis $[3,4,5,6]$.

It occurs commonly in children and young adult between 5-35yrs and has equal sex incidence [3]. However some studies have shown slight female predominance [1, 4, 7]. Etiology and the genetic abnormality of FLC are

unknown. Studies have shown that they lack mutation in the gene most commonly mutated in typical HCC (TP53

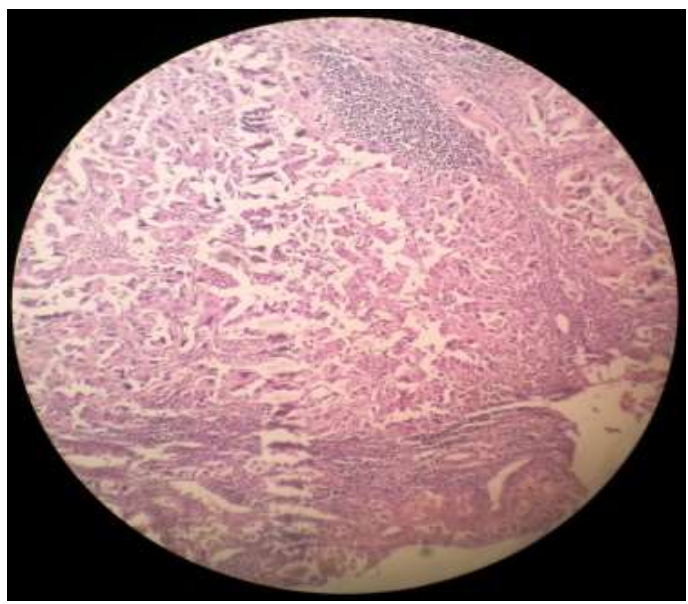

Fig 4: Large polygonal neoplastic cell clusters separated by fibrosis arranged in lamellar fashion

\& CTNN B 4). FLC generally present with a nonspecific clinical signs and symptoms, which include abdominal pain, fatigue, malaise and weight loss. Overall the most common physical finding is an abdominal mass or hepatomegaly. However a wide variety of unusual presentations have also been described.

Laboratory findings in FLC are usually normal. In our case also liver profile was normal. Alpha feto protein (AFP) levels are typically normal in FLC [8]. Craig et al highlighted the distinctive histologic features of FLC 
which consist of deeply eosinophilic neoplastic hepatocytes and fibrosis arranged in a lamellar fashion around the neoplastic hepatocytes [3]. Because of its characteristic histological features most case of FLC are readily diagnosed from metastatic site. Cytologically FLC is characterized by oncocytic hepatocytes which are three times the size of normal hepatocytes [9, 10].

The treatment of choice in hepatic lesion is complete resection. Inoperable cases of FLC are benefited from adjuvant chemotherapy. FLC has high operatability rate and better prognosis compare to conventional $\mathrm{HCC}[3,4$, $11]$.

Kakar S et al in his study found that prognosis of FLC and conventional $\mathrm{HCC}$ without cirrhosis were similar which reflect that probably the better prognosis of FLC is due to lack of cirrhosis in it [12].

Our case of FLC presented with cervical lymph node metastasis which is a rare presentation. To our knowledge very few cases of FLC has been reported from India. One largest series of 6 cases was reported by Singhal et al in 2002 [13].

Two more cases were reported, one was FLC associated with Non Bacterial Thrombotic Endocarditis in a young $17 \mathrm{yr}$ male [14] and the other case was of a 25 years Indian female in which diagnosis was made based on cytological features of FLC [10].

\section{Conclusion}

Clinical recognition of this variant of $\mathrm{HCC}$ is important because of excellent result of complete surgical resection. And a definite diagnosis of this variant of HCC can be made only by histopathological examination of the lesion. Clinicians should keep this variant of HCC in mind in young adult without underlying hepatitis or cirrhosis.

\section{Funding: Nil}

\section{Conflict of interest: Nil}

Permission from IRB: Yes

\section{References}

1. El-Serag HB, Davila JA. Is fibrolamellar carcinoma different from hepatocellular carcinoma? A US population-based study. Hepatology. Mar 2004; 39(3):798-803.
2. Edmondson HA. Differential diagnosis of tumors and tumor-like lesions of liver in infancy and childhood. $A M A$ J Dis Child. Feb 1956; 91(2):168-86.

3. Craig JR, Peters RL, Edmondson HA, et al. Fibrolamellar carcinoma of the liver: a tumor of adolescents and young adults with distinctive clinicopathologic features. Cancer. Jul 15 1980; 46(2):372-9.

4. Farhi DC, Shikes RH, Murari PJ, et al. Hepatocellular carcinoma in young people. Cancer. Oct 15 1983; 52(8):1516-25

5. Berman MM, Libbey NP, Foster JH. Hepatocellular carcinoma. Polygonal cell type with fibrous stroma--an atypical variant with a favorable prognosis. Cancer. Sep 15 1980; 46(6):1448-55.

6. Vecchio FM. Fibrolamellar carcinoma of the liver: a distinct entity within the hepatocellular tumors. A review. Appl Pathol. 1988; 6(2):139-48.

7. O. Soreide, A. Czerniak, H. Bradpiece, S. Bloom, and L. Blumgart, "Characteristics of fibrolamellar hepatocellular carcinoma. a study of nine cases and a review of the literature," American Journal of Surgery, vol. 151, no. 4, pp. 518-523, 1986.

8. Haratake J, Horie A. A histopathologic comparative study of European cases of Fibrolamellar carcinoma and Japanese cases of sclerosing hepatocellular carcinoma. Gan No Rinsho. 1989 Jun; 35(7):793-8.

9. Perez-Guillermo M, Masgrau NA, García-Solano J, et al. Cytologic aspect of fibrolamellar hepatocellular carcinoma in fine-needle aspirates. Diagn Cytopathol. Sep 1999; 21(3):180-7.

10. Gulati G, Saran RK. Fine needle aspiration cytology of fibrolamellar hepatocellular carcinoma: Recongnizing the oncocytic hepatocyte. Inian J Pathol Microbiol 2009; 52:288-9.

11. Ward SC, Waxman S. Fibrolamellar carcinoma: a review with focus on genetics and comparison to other malignant primary liver tumors. Semin Liver Dis. Feb 2011; 31(1):61-70.

12. Kakar S, Burgart LJ, Batts KP, et al. Clinicopathologic features and survival in fibrolamellar carcinoma: comparison with conventional hepatocellular carcinoma with and without cirrhosis. Mod Pathol. Nov 2005; 18(11):1417-23. 
13. Singhal D, Vasdev N, Gupta S, Soin AS, Nayak NC, Nundy S. Fibrolamellar hepatocellular carcinoma: Not a rare tumor in India and a possible new marker. J Gastroenterol Hepatol 2002; 17:A67.
14. Vaideeswar P, Pandit MJ, Deshpande JR, Sivaraman A, Vora IM. Fibrolamellar carcinoma of the liver: An unusual presentation. J Postgrad Med 1993; 39:159-61.

\section{How to cite this article?}

Nayak R, Jain S. A Rare Case of Fibrolamellar Hepatocellular Carcinoma with Unusual Presentation in a Young Indian Female- a case report. Int J Med Res Rev 2014;2(4):385-388. doi:10.17511/ijmrr.2014.i04.21 